\title{
THE MEASUREMENT OF INNOVATION EFFICIENCY OF CHINESE HIGH-TECH INDUSTRY USING DATA ENVELOPMENT ANALYSIS
}

\author{
Ling JIANG ${ }^{1}$ - Yunyu JIANG ${ }^{2}$ - Zhijun $\mathrm{WU}^{3}$ - Dongsheng LIAO $^{4}-$ Runfa XU \\ ${ }^{1}$ School of Economics and Trade, Guangdong University of Foreign Studies, Guangzhou 510006, \\ China.E-mail: jling163@163.com (corresponding author) \\ ${ }^{2}$ School of Accounting, Guangdong University of Foreign Studies, Guangzhou 510006, China. \\ E-mail:908646457@qq.com \\ ${ }^{3}$ Guangdong University of Foreign Studies, Guangzhou 510420, China.E-mail: kumau@126.com \\ ${ }^{4}$ Business School, Guangxi University for Nationalities, Nanning 530006, China. \\ E-mail: lzylds@163.com
}

${ }^{5}$ School of Accounting, Guangdong University of Foreign Studies, Guangzhou 510006, China. E-mail:306656782@qq.com

In the era of knowledge economy, a country's economic competitiveness depends largely on the development level of high-tech industry. This paper evaluates the efficiency of China's high-tech industry in 31 provinces in 2012 with data envelopment analysis. The empirical results are summarized as following. Firstly, when the effects of exogenous environmental variables are not controlled, the comprehensive technical efficiency of 31 provinces will be overestimated, the pure technical efficiency will be underestimated, and the scale efficiency value will be overestimated. Secondly, after eliminating the environmental impact, the comprehensive technical efficiency of 31 provinces with the average of 0.395 is rather low, due to the low scale efficiency.

Keywords: high-tech industry, technical efficiency, data envelopment analysis 


\section{INTRODUCTION}

There is a considerable agreement that a country's economic competitiveness largely depends on the development level of high-tech industry in the era of knowledge economy. The sound development of high-tech industry has played an important role in the industrial structure promotion as well as the economic growth mode transformation in China. Compared with conventional industries, high-tech industry relies more heavily on fund investment and high-quality human capital investment (Fojtik and Lányi 2009).

In light of the High-tech Industry Statistical Classification Catalog released by the National Bureau of Statistics of China in 2002, the statistical range of Chinese high-tech industry includes aerospace and aviation industry, electronics and communications manufacturing industry, computer and office equipment manufacturing industry, medicine industry, medical equipment and instrumentation manufacturing industry. The development of high-tech industry has made great contribution to the commercialization and industrialization of many science and technology research achievements. In recent years, the high-tech industry in China is booming. Several high-tech industrial cluster districts are formed in some regions such as Pearl River Delta, Yangtze River Delta and the Around Bohai Sea Area etc. During the turn of the $21^{\text {st }}$ century, the main business income of high-tech industry in China increased from 1,005.01 billion RMB in 2000 to 10,228.4 billion RMB in 2012, total profit from 67.31 billion RMB to 618.63 billion RMB, and export delivery value from 339.6 billion RMB to 4.67011 trillion RMB. Specifically, the electronics and communications manufacturing industry accounted for $51.6 \%$ in the proportion of main business income in 2012, followed by computer and office equipment manufacturing industry and medicine industry, accounting for $21.6 \%$ and $17.0 \%$, respectively. As to the proportion of total profit, the top three were electronics and communications manufacturing industry, medicine industry, computer and office equipment manufacturing industry, accounting, respectively, for $43.3 \%, 30.2 \%$ and $12.8 \%$. Electronics and communications manufacturing industry, computer and office equipment manufacturing industry, and medical equipment and instrumentation manufacturing industry ranked the highest in the proportion of export delivery value, accounting for $57.9 \%, 36.2 \%$ and $2.6 \%$, respectively.

Concerning that the growth and technological innovation of high-tech industry relies heavily on high investment, this paper aims to calculate and evaluate the innovation efficiency of high-tech industry in China. In addition, the study sheds light on the external factors in the innovation efficiency, trying to ascertain their economic effects and find out possible ways for improvement. 
Existing studies from Chinese scholars provided some significant insights into innovation efficiency. Zhu and $\mathrm{Xu}$ (2006) used the stochastic frontier analysis technique to calculate R\&D efficiency of high-tech industry in China, which came out to be rather low but grew with steady steps. Liu and Li (2013) indicated the regional differences in technological innovation efficiency. The innovation efficiency of high-tech industry in the east area of China was higher than in the west. Huo and Guo et al. (2012) estimated the regional differences in IT investment efficiency of China's manufacturing enterprises. Also, several prior papers selected a specific industry in China to estimate its operational efficiency, such as telecom industry, information industry and logistics industry (see Han and Yuan 2012; Li 2011; Zhong 2010). Gong (2008) used the methods of four-stage DEA and Bootstrapped DEA to assess the efficiency of the government service provision. The present study aims to estimate the innovation efficiency of hightech industry in China while controlling the exogenous environmental variables, based on the four-stage DEA model suggested by Fried et al. (1999).

The remainder of this paper is structured as follows. Section 2 describes the methodology and empirical model. Section 3 explains the variables and data sources. Section 4 discusses the empirical results. Section 5 draws conclusions.

\section{METHODOLOGY AND MODELS}

\subsection{DEA approach}

Efficiency is a comprehensive evaluation index for producer performance. As a kind of non-parametric approach, Data Envelopment Analysis (DEA) has been widely used to measure the efficiency of firms or public-sector agencies (Gökgöz 2010). The original model of DEA, namely the CCR model, was presented in the research of Charnes, Cooper and Rhodes (1978) to measure the efficiency of a decision-making unit (DMU). This model was applicable only to technologies characterized by constant returns to scale. The BCC model, which was presented in the research of Banker, Charnes and Cooper (1984), extended the CCR model to accommodate technologies that exhibited variable returns to scale. The efficiency measured with this model was known as technical efficiency or TE for short, which could be further explained as pure technical efficiency (PTE) multiplied by the scale efficiency (SE) (Bojnec et al. 2014). As the conventional DEA model has been well-developed, its detailed linear programming principles are no longer explained here. 


\subsection{Four-stage DEA}

Without considering the influence on efficiency caused by different external environment of each decision subject and the random error etc., the classic DEA approach attributed the whole deviation towards efficiency frontier to managerial inefficiency, in which the actual level of efficiency might be overestimated or underestimated by the efficiency score.

The four-stage DEA model presented by Fried et al. (1999) could assess the decision-making unit (DMU) efficiency better. Furthermore, it revised the effects to efficiency assessment caused by exogenous environmental variables, which helped calculate the efficiency values more accurately. Four steps were described as follows.

The first stage was building a conventional DEA-BCC model. As inputs are easier to control than outputs, this paper uses an input oriented BCC model to calculate the efficiency and slack value of each DMU.

The second stage was building Tobit regression models; $m$ represented the input quantity. The explained variable was the sum of slacks for each input (i.e. the amount of radial slacks plus the amount of non-radial slacks), while the explanatory variable was the exogenous environmental variable of DMU. The regression model is expressed as follows.

$$
S_{i k}=\alpha_{1}+\beta_{i} Z_{k}+u_{1} \quad i=1,2, \ldots, m ; \mathrm{k}=1,2, \ldots, n
$$

where $S_{i k}$ was a vector of the i-th total input slacks for the k-th DMU and $Z_{k}=\left(Z_{1 k}\right.$, $Z_{2 k}, \ldots, Z_{p k}$ ) was the $\mathrm{p}$-th observable environmental variable, given the constant term $\alpha_{i}, \beta_{i}$ was the coefficient for environment variable, and $u_{i}$ was the random error.

The third stage was adjusting input of each DMU according to Tobit regression results. In the present paper, those inputs of DMUs relatively better are chosen to make upward adjustments. In addition, input quantities of other samples are adjusted based on the input quantity of the most effective DMU. The adjustment equation is presented as follows.

$$
X_{i k}^{A}=X_{i k}+\left\{\max \left[z_{k} \beta^{i}\right]-z_{k} \beta^{i}\right\} \quad i=1,2, \ldots, m ; \mathrm{k}=1,2, \ldots, n
$$

where $X_{i k}$ is the original input, $X_{i k}^{A}$ is the input after adjustment, and $\beta_{i}$ is the parameter estimation value of environment variable. Equation 2 adjusts all DUMs into the same environment, under a basic idea that the maximum amount of slack corresponds to the worst external environment. In other words, when a DMU is in the worst external environment $\max \left[z_{k} \beta^{i}\right]-z_{k} \beta^{i}=0$ then $X_{i k}^{A}=X_{i k}$, the original input is not adjusted; when being in a better external environment 
$\max \left[z_{k} \beta^{i}\right]-z_{k} \beta^{i}>0$ the original input is then adjusted upward. After such adjustments, all DMUs are ultimately in the same environment.

In the fourth stage, the original output data was used for representing outputs, while the original input data were replaced by adjusted data. BCC model was operated again to assess and measure the efficiency values of DMUs excluding the impact of the external environmental effects.

Fried et al. (2002) amended the four-stage DEA, including using the input slacks as opportunity cost of DMUs, applying the cost stochastic frontier analysis (SFA) model instead of Tobit regression model in the second stage, and decomposing the mixed errors into two parts with the help of SFA model. One was statistical noise following normal distribution with zero mean and homoscedasticity; the other was managerial inefficiency that obeys semi-normal distribution. This adjustment model incorporated environmental effects, managerial inefficiency and statistical noise into analytical framework, but required adequate samples to ensure the consistency of the two estimated errors, as pointed out by Fried et al. (2002). Therefore, this approach is not adopted in the present paper.

\section{VARIABLES AND DATA}

\subsection{Data sources}

Given the data availability and research needs, the input and output data of hightech industry in China's 31 provinces, municipalities and autonomous regions in 2012 are used. Such data come from the China Statistical Yearbook and China Statistical Yearbook of High-tech Industry of previous years. DEAP2.1 and EViews6.0 are used for analyzing the data.

\subsection{Input and output variables}

Based on the industry characteristics and development direction of high-tech industry, the sales of new products and the amounts of patents are selected as output indicators; along with the R\&D capital stock and the R\&D personnel FTEs as input indicators.

As the sales of new products (billion RMB) felicitously reflect the acceptance in markets, and directly represent the value of technological innovations, they are chosen as an output indicator. Meanwhile, the amount of patents is an output indicator that is applied internationally for technology innovation measurement, which could be used for evaluating R\&D performance of high-tech industry. 
Here, the amount of patent authorizations is chosen as the other innovation output indicator.

When it comes to innovation investments, both chosen input indicators - inputs of R\&D personnel and capital - are key factors in R\&D activities. By means of perpetual inventory method, the R\&D capital stock is calculated based on the practices of Coe and Helpman (1995) etc. Considering the features of high-tech industry, $15 \%$ is employed as the depreciation rate. As to R\&D personnel input, R\&D personnel FTEs (annual full time equivalent per capita) are selected.

\subsection{Environmental variables}

While selecting environmental variables, those factors in the efficiency of hightech industry without being subjectively controlled by samples should be considered. Accordingly, this paper chooses three environmental variables of regional GDP (billion RMB) that would be taken the logarithm during data processing to reflect the economic development of a region as a whole, the level of opening with proportion of regional export delivery as proxy variable, and government support to high-tech industry, with the proportion of government funds in R\&D internal expenditures as environmental proxy variables.

\section{THE EMPIRICAL RESULTS}

\subsection{Conventional DEA empirical results}

Based on DEAP2.1, this paper estimates the efficiency value of high-tech industry in 31 provinces, municipalities and autonomous regions. The results are reported in Table 1. On the whole, the average comprehensive technical efficiency of China's high-tech industry is 0.480 ; while the mean values of pure technical efficiency and scale efficiency are 0.624 and 0.753 , respectively, without considering the impact of external environmental factors.

From the view of each province, municipality or autonomous region, only Tianjin and Tibet reach the technical efficiency frontier, while other regions still have room for efficiency improvement to various degrees. Except for Beijing City, Ningxia Hui Autonomous Region and provinces such as Jiangsu, Guangdong, Hainan and Qinghai, the pure technical efficiency in other regions is lower than the scale efficiency; meanwhile, the mean value of pure technical efficiency is less than that of scale efficiency, which indicates that low pure technical effi- 
Table 1. Technical efficiency of high-tech industry in various regions of China in 2012

\begin{tabular}{lccc|lccc}
\hline Region & TE & PTE & SE & Region & TE & PTE & SE \\
\hline Beijing & 0.683 & 1.000 & 0.683 & Hubei & 0.341 & 0.421 & 0.808 \\
Tianjin & 1.000 & 1.000 & 1.000 & Hunan & 0.589 & 0.677 & 0.869 \\
Hebei & 0.362 & 0.400 & 0.906 & Guangdong & 0.578 & 1.000 & 0.578 \\
Shanxi & 0.455 & 0.551 & 0.825 & Guangxi & 0.406 & 0.502 & 0.810 \\
Inner Mongolia & 0.423 & 0.432 & 0.979 & Hainan & 0.554 & 0.870 & 0.636 \\
Liaoning & 0.266 & 0.400 & 0.664 & Chongqing & 0.720 & 0.806 & 0.893 \\
Jilin & 0.564 & 0.672 & 0.839 & Sichuan & 0.515 & 0.621 & 0.830 \\
Heilongjiang & 0.130 & 0.203 & 0.640 & Guizhou & 0.305 & 0.522 & 0.585 \\
Shanghai & 0.393 & 0.607 & 0.647 & Yunnan & 0.396 & 0.607 & 0.653 \\
Jiangsu & 0.780 & 1.000 & 0.780 & Tibet & 1.000 & 1.000 & 1.000 \\
Zhejiang & 0.441 & 0.515 & 0.857 & Shanxi & 0.173 & 0.231 & 0.751 \\
Anhui & 0.676 & 0.815 & 0.830 & Gansu & 0.376 & 0.459 & 0.819 \\
Fujian & 0.661 & 0.671 & 0.984 & Qinghai & 0.151 & 0.703 & 0.214 \\
Jiangxi & 0.389 & 0.421 & 0.923 & Ningxia & 0.696 & 1.000 & 0.696 \\
Shandong & 0.489 & 0.605 & 0.808 & Xinjiang & 0.018 & 0.127 & 0.143 \\
Henan & 0.352 & 0.508 & 0.693 & Mean & 0.480 & 0.624 & 0.753 \\
\hline
\end{tabular}

$\mathrm{TE}=$ technical efficiency; $\mathrm{PTE}=$ pure technical efficiency; $\mathrm{SE}=$ scale efficiency.

ciency is the constraints on the efficiency improvement of high-tech industry in most regions. However, it is somewhat surprising that Tibet reaches the technical efficiency frontier, which needs further analysis and confirmation.

\subsection{Tobit regression}

By means of Tobit regression model, the relationship between the external environment and the input slacks is estimated, with input slacks of R\&D capital and $R \& D$ personnel evaluated in the first phase as the explained variable, while regional GDP, proportion of regional export delivery and proportion of government fund in $R \& D$ internal expenditures as explanatory variables. The estimation results are shown in Table 2.

Given that the input slacks are regressed against the environmental variables, a negative regression coefficient of environmental variables may indicate the negative correlation between environmental variables and the input slacks. That is to say, the environmental variables help reduce the waste of inputs and benefit efficiency improvements. In contrast, a positive regression coefficient may indicate the positive correlation between environmental variables and the input slacks. In such case, external environmental factors may go against efficiency improvements. 
Table 2. Results of Tobit in second phase

\begin{tabular}{|c|c|c|c|c|c|}
\hline \multicolumn{3}{|c|}{ Slacks of R\&D capital stock } & \multicolumn{3}{|c|}{ Slacks of R\&D personnel FTEs } \\
\hline $\begin{array}{l}\text { Explanatory } \\
\text { variables }\end{array}$ & $\begin{array}{l}\text { Parameter } \\
\text { estimates }\end{array}$ & P values & $\begin{array}{l}\text { Explanatory } \\
\text { variables }\end{array}$ & $\begin{array}{l}\text { Parameter } \\
\text { estimates }\end{array}$ & $P$ values \\
\hline Constant term & -326.4288 & $0.0002 * * *$ & Constant term & -57266.23 & $0.0005 * * *$ \\
\hline $\begin{array}{l}\text { Regional GDP } \\
\text { (Logarithm) }\end{array}$ & 36.16465 & $0.0001 * * *$ & $\begin{array}{l}\text { Regional GDP } \\
\text { (Logarithm) }\end{array}$ & 6734.370 & $0.0001 * * *$ \\
\hline Level of opening & -3.204298 & $0.0201 * *$ & Level of opening & -756.0001 & $0.0074 * * *$ \\
\hline $\begin{array}{l}\text { Government } \\
\text { support }\end{array}$ & 124.5495 & $0.0650 *$ & $\begin{array}{l}\text { Government } \\
\text { support }\end{array}$ & -2226.321 & $0.0865^{*}$ \\
\hline
\end{tabular}

$* * *$ Significant at $5 \% ; * *$ significant at $1 \%$; significant at $10 \%$.

Table 2 shows that the coefficients of each environmental variable against both input slacks are always significant, which confirms the significant effect of external environmental factors on the input redundancy in each region. As to slacks of $R \& D$ capital stock, the coefficient of the opening level is negative and significant at $5 \%$, indicating that external environment of export expansion is conducive to enhance the high-tech industrial efficiency. When it comes to the input slacks of R\&D personnel, both coefficients of opening level and government support are negative but significant, indicating that the increase of export and government funds on high-tech industry helps promote the efficiency.

\subsection{DEA after input adjustment}

The original input variables are then adjusted based on Equation 2 presented above, and the original input data are replaced with those adjusted ones. Taking the original output data as outputs, the DEA-BCC model is operated again to calculate and evaluate the efficiency of DMUs. In this way, the obtained efficiency values exclude the impacts of external environmental effects. Results are expressed in Table 3.

From the comparison of Table 1 and Table 3, significant changes are found in the regional efficiency in high-tech industry, with environmental effects being excluded. With regard to the average efficiency of observed regions, the DEA results after input adjustments are expressed as follows. The technical efficiency declines, compared with the first stage, from 0.480 to 0.395 ; pure technical efficiency rises significantly, from 0.624 to 0.796 ; however, there is a more significant drop from 0.753 to 0.467 in scale efficiency.

From the view of each region, Beijing City, Tianjin City and Jiangsu Province reach the technical efficiency frontier after adjustment. As technical efficiency in 
Table 3. Technical efficiency of regional high-tech industry in the same environment in 2012

\begin{tabular}{lccc|lccc}
\hline Region & TE & PTE & SE & Region & TE & PTE & SE \\
\hline Beijing & 1.000 & 1.000 & 1.000 & Hubei & 0.454 & 0.653 & 0.696 \\
Tianjin & 1.000 & 1.000 & 1.000 & Hunan & 0.589 & 0.984 & 0.599 \\
Hebei & 0.332 & 1.000 & 0.332 & Guangdong & 0.914 & 1.000 & 0.914 \\
Shanxi & 0.102 & 0.787 & 0.130 & Guangxi & 0.144 & 0.879 & 0.164 \\
Inner Mongolia & 0.034 & 1.000 & 0.034 & Hainan & 0.056 & 0.488 & 0.114 \\
Liaoning & 0.471 & 0.756 & 0.623 & Chongqing & 0.320 & 0.790 & 0.405 \\
Jilin & 0.229 & 0.929 & 0.246 & Sichuan & 0.668 & 0.882 & 0.757 \\
Heilongjiang & 0.186 & 0.858 & 0.217 & Guizhou & 0.213 & 0.710 & 0.300 \\
Shanghai & 0.586 & 0.645 & 0.909 & Yunnan & 0.126 & 0.834 & 0.151 \\
Jiangsu & 1.000 & 1.000 & 1.000 & Tibet & 0.004 & 0.383 & 0.011 \\
Zhejiang & 0.645 & 0.674 & 0.956 & Shanxi & 0.258 & 0.545 & 0.474 \\
Anhui & 0.618 & 0.988 & 0.625 & Gansu & 0.062 & 0.687 & 0.091 \\
Fujian & 0.725 & 0.817 & 0.888 & Qinghai & 0.001 & 0.396 & 0.002 \\
Jiangxi & 0.290 & 0.723 & 0.401 & Ningxia & 0.035 & 0.480 & 0.073 \\
Shandong & 0.848 & 0.860 & 0.986 & Xinjiang & 0.002 & 1.000 & 0.002 \\
Henan & 0.335 & 0.928 & 0.361 & mean & 0.395 & 0.796 & 0.467 \\
\hline
\end{tabular}

$\mathrm{TE}=$ technical efficiency; PTE $=$ pure technical efficiency $\mathrm{SE}=$ scale efficiency.

Tibet is only 0.004 , It reached the first stage of the technical efficiency frontier is not confirmed, which is consistent with prevailing wisdom and industrial developments. Whilst, technical efficiency rises to certain extent in twelve regions, namely Beijing, Liaoning, Heilongjiang, Shanghai, Jiangsu, Zhejiang, Fujian, Shandong, Hubei, Guangdong, Sichuan and Shanxi, showing that the industry efficiency in these regions in fact is better than it seems to be. Except for Hainan, Chongqing, Tibet, Qinghai and Ningxia, pure technical efficiency in most regions rises to a certain degree, indicating that the low technical efficiency in these regions in the first stage is partly due to poor external environment instead of poor technical management level.

After input adjustment, except for six regions that are exactly those with welldeveloped high-tech industry and achieve scale economies, namely Beijing, Shanghai, Jiangsu, Zhejiang, Shandong and Guangdong, scale efficiency of most other regions declines sharply. This situation suggests that the scale efficiency in high-tech industry is affected by environmental factors. On the other hand, these regions need to scale up on the basis of current development to achieve scale economies so as to promote scale efficiency. The fact that scale efficiency is far below pure technical efficiency drives down the comprehensive technical efficiency. It can be seen that low scale efficiency is an important restriction on efficiency improvement of high-tech industry in China. 
To present the regional efficiency distribution more clearly, 0.8 is taken as a critical point to classify the regions into four groups according to their pure technical efficiency and scale efficiency, as shown in Table 4.

Table 4. Distribution of the regions

\begin{tabular}{lll}
\hline Item & High pure technical efficiency & Low pure technical efficiency \\
\hline $\begin{array}{l}\text { High scale } \\
\text { efficiency }\end{array}$ & $\begin{array}{l}\text { Beijing, Tianjin, Jiangsu, } \\
\text { Fujian, Guangdong, Shandong }\end{array}$ & Zhejiang, Shanghai \\
\hline $\begin{array}{l}\text { Low scale } \\
\text { efficiency }\end{array}$ & $\begin{array}{l}\text { Hebei, Inner Mongolia, Jilin, } \\
\text { Heilongjiang, Anhui, Henan, Hunan, } \\
\text { Guangxi, Sichuan, Yunnan, Xinjiang }\end{array}$ & $\begin{array}{l}\text { Liaoning, Jiangxi, Shanxi, Hubei, } \\
\text { Hainan, Chongqing, Guizhou, Tibet, } \\
\text { Shanxi, Gansu, Qinghai, Ningxia }\end{array}$ \\
\hline
\end{tabular}

Table 4 shows four types of different innovation modes among those regions. The first type includes Beijing, Tianjin, Jiangsu and other three regions, in which both pure technical efficiency and scale efficiency are higher than 0.8 . These regions may need less room for efficiency improvement. The second type includes only Zhejiang Province and Shanghai City, in which pure technical efficiency is lower than 0.8 while scale efficiency is higher. Regions of this type should focus on the pure technical efficiency, going further with the system and management level improvement, and optimizing resource allocation to reduce waste of investment. The third type includes eleven regions such as Hebei, Inner Mongolia etc., in which pure technical efficiency is higher than 0.8 and scale efficiency is lower. Improvement direction for these regions is to enhance the scale efficiency by for instance - increasing investments in technological innovation and expanding the scale of high-tech industry in order to achieve scale economies. Regions of the fourth type includes twelve regions such as Liaoning, Jiangxi etc., in which both pure technical efficiency and scale efficiency are lower than 0.8. Management level of high-tech industry in those regions is relatively backward. Moreover, industrial scale is not achieved there for the lack of innovation input. Thus there is greater room for innovation efficiency improvement in these regions, strengthening the system construction to improve management level, and meanwhile enhancing the scale efficiency is necessary.

\subsection{Regional analysis}

The development of high-tech industry is closely related with that of economy in each region. The same is true in China where regional differentiation is quite 
Table 5. Comparison of Eastern, Central and Western high-tech industrial efficiency

\begin{tabular}{lccc|lccc}
\hline Phase I & TE & PTE & SE & $\begin{array}{l}\text { After input adjustment } \\
\text { (Phase IV) }\end{array}$ & TE & PTE & SE \\
\hline $\begin{array}{l}\text { National } \\
\text { average }\end{array}$ & 0.480 & 0.624 & 0.753 & $\begin{array}{l}\text { National } \\
\text { average }\end{array}$ & 0.395 & 0.796 & 0.467 \\
Eastern & 0.564 & 0.733 & 0.777 & Eastern & 0.689 & 0.840 & 0.793 \\
Central & 0.433 & 0.520 & 0.822 & Central & 0.298 & 0.873 & 0.347 \\
Western & 0.435 & 0.608 & 0.658 & Western & 0.169 & 0.671 & 0.227 \\
\hline
\end{tabular}

$\mathrm{TE}=$ technical efficiency; $\mathrm{PTE}=$ pure technical efficiency; $\mathrm{SE}=$ scale efficiency.

obvious. Following the conventional taxonomy of regions, those 31 regions are sorted into Eastern China, Central China and Western China. ${ }^{1}$

In Table 5, technical efficiency in Eastern China (0.564) ranks the highest without concerning environmental factors, followed by Western China (0.435) and Central China (0.433). To our surprise, high-tech industry in Western China turns out to be more efficient than Central China. Besides, scale efficiency in both Central and Western China is significantly higher than the pure technical efficiency. Such results are quite different from the current development situation of high-tech industry there.

After excluding the impact of environmental factors, eastern technical efficiency (0.689) remains the highest, in line with our anticipation. The TE in Central China (0.298) follows, but TE in Western China is only 0.169. On the whole, Eastern innovation efficiency performs the best, followed by Central, and Western the worst. The development of high-tech industry is regionally imbalanced. Besides, after environmental factors are excluded, innovation efficiency in the three areas features higher pure technical efficiency and low scale efficiency. As China is a developing country, the high-tech industry still has large room for improvement. Due to diseconomies of scale, technological potential and resource potential have not been fully played out; these regions need to effectively enlarge the scale of the high-tech industry to improve scale efficiency.

In eastern China, especially the Pearl River Delta, Yangtze River Delta and the Around Bohai Sea Area, the economy develops rapidly. As a result, the promotion of high-tech industry efficiency and sustainable technological innovation are supported by human capital accumulation, investment of information technology

Eastern China includes 11 regions of Beijing, Tianjin, Hebei, Liaoning, Shanghai, Jiangsu, Zhejiang, Fujian, Shandong, Guangdong and Hainan; Central China includes 10 regions of Shanxi, Inner Mongolia, Jilin, Heilongjiang, Anhui, Jiangxi, Henan, Hubei, Hunan and Guangxi; Western China includes Sichuan, Chongqing, Guizhou, Yunnan, Shaanxi, Gansu, Qinghai, Ningxia, Tibet and Xinjiang. 
infrastructure and preferential policies. Due to the low level of economic development in central and western China, the infrastructure construction and investment, R\&D personnel and R\&D capital investment are not sufficient. As the development of high-tech industry there is still in an early stage of extensive mode, it is easy to understand the low industrial efficiency. With increasing governmental investments as well as some preferential policies in taxation, investment and resources, the soft and hard environments in western China are improved. In addition, upgrading of the industrial structure and the industrial transfer from Eastern China bring continuous influence to impel industrial restructuring in Western China, where PTE performs well, but SE is yet to be improved.

By comparison, it can be seen that the TE of regional high-tech industry would be overvalued when conventional DEA approach is followed without environmental control. And PTE would be undervalued while SE is overvalued, in which overestimation of the latter would be greater than underestimation of the former. To some extent, the four-stage DEA approach can 'filter' the impact of external environment and assess innovation efficiency better.

\section{CONCLUSION}

With four-stage DEA approach, this paper estimates and evaluates the technical efficiency of the high-tech industry in 31 provinces, municipalities and autonomous regions in China in 2012. The results are presented as follows.

The TE of regional high-tech industry would be overvalued when conventional DEA approach is followed without environmental control. And PTE would be undervalued while SE is overvalued, in which overestimation of the latter would be greater than underestimation of the former. To some extent, the fourstage DEA approach can 'filter' the impact of external environment and assess innovation efficiency better.

After excluding the impact of external environment, the efficiency of hightech industry in each region has poor performance. The TE declines, compared with the first stage, from 0.480 to 0.395 ; the PTE rises significantly, from 0.624 to 0.796; and, there is a more significant drop from 0.753 to 0.467 in SE. Therefore, the low efficiency mainly results from the low scale efficiency.

From a regional perspective, after eliminating the impact of external environment, eastern innovation efficiency performs the best, followed by central, and western the worst; innovation efficiency in the three areas features higher pure technical efficiency and low scale efficiency. Thus, each region should adopt appropriate measures targeted against efficiency loss. For example, the introduction of advanced management concepts and methods is needed for regions with 
lower PTE so as to strengthen relevant innovation and improve management level; contrarily, those regions with lower scale efficiency need to effectively enlarge the scale of high-tech industry to enhance scale efficiency. All in all, the key point for high-tech industry development is increasing input of $R \& D$ capital and personnel, constantly offering new products to market needs and possessing intellectual property.

\section{ACKNOWLEDGEMENTS}

This paper is supported by the Ministry of Education of P.R.C (11JZD021) and Guangdong Science and Technology Department (2013B070206057).

\section{REFERENCES}

Banker, R.D., Charnes, A. and Cooper, W.W. (1984). Some models for estimating technical and scale inefficiencies in Data Envelopment Analysis. Management Science, 30(9), 1078-1092.

Charnes, A., Cooper, W.W. and Rhodes E. (1978). Measuring the efficiency of decision making units. European Journal of Operational Research, 2(6), 429-444.

Coe, S. and Helpman, M. (1995). International R\&D spillovers. European Economic Review, 39(5), 859-887.

Fried, H.O., Lovell, C.A.K., Schmidt, S.S. and Yaisawarng, S. (2002). Accounting for environmental effects and statistical noise in Data Envelopment Analysis. Journal of Productivity Analysis, 17(1-2), 157-174.

Fried, H.O., Schmidt, S.S. and Yaisawarng, S. (1999). Incorporating the operating environment into a nonparametric measure of technical efficiency. Journal of Productivity Analysis, 12(3), 249-267.

Gong, F. (2008). Local public safety service delivery efficiency assessment - Based on a four-stage DEA and Bootstrap approach. Management World, 4, 80-90.

Han, L. and Yuan, C. (2012). The evaluation of the operational efficiency and research on influencing factors of China's Telecom Industry - An empirical analysis based on four-stage DEA. Industrial Economics Research, 3, 26-32.

Huo, M. and Guo, W. et al. (2012). Research on regional difference of IT investment efficiency of manufacturing enterprises in China. Soft Science, 8, 1-9.

Li, L. (2011). The efficiency of China's information industry by using the empirical research in three stages DEA. Statistics \& Decision, 16, 84-86.

Liu,W. and Li, X. (2013). The Chinese high-tech industry of technology innovation efficiency in the different region - Based on a three-stage DEA model and Bootstrap approach. Research on Financial and Economic Issues, 8, 20-28.

Zhong, Z. (2010). Research on the efficiency of logistics industry in China - Based on a three-stage DEA model. Journal of Finance and Economics, 9, 80-90.

Zhu, Y. and Xu, K. (2006). The empirical research on R\&D efficiency of Chinese high-tech industry. China Industrial Economy, 11, 38-45. 